\title{
Differences in Behavior Preventing Smoking (Reviewed Based on Planning Behavior Theories) between Before and After Intervention with Jigsaw Technique
}

\author{
Toghur Arifani Lubis ${ }^{1}$, R. Kintoko Rochadi ${ }^{2}$, Namora Lumongga Lubis ${ }^{3}$ \\ 1,2,3 Faculty of Public Health, Universitas Sumatera Utara, Medan, Indonesia \\ Email: toghurarifani@yahoo.com
}

\begin{abstract}
:
Various interventions to prevent smoking at this time have been carried out on modifications of peer influence, not only to improve their knowledge, adolescents need to be given skills to control themselves, especially from peer influences with the aim that smoking is not socially accepted for adolescents and cooperative learning is a suitable method. Cooperative learning is successfully used by teachers and researchers at various levels of education, the field of health, especially public health education, and is proven effective when someone teaches his peers about health. This study uses a cooperative learning model with a jigsaw technique, aimed at analyzing differences in smoking prevention behavior (based on planned behavior theory consisting of attitudes, subjective norms, behavioral control, and intentions) between before and after the intervention. Research with quasi experiment type has been carried out in MTS Amin Darussalam of 20 students who were collected by purposive sampling technique, data were collected by questionnaire and analyzed by Chi-Square. The results showed that there were differences in attitudes, subjective norms, PBC and intentions between before and after the intervention with jigsaw.

Keywords:

jigsaw; attitude; subjective norms; PBC; intention; smoke
\end{abstract}

\section{Introduction}

Based on the Global Youth Tobacco Survey in Indonesia (2014), it was found that $19 \%$ of teenagers smoked, while in North Sumatra Riskesdas showed almost half $(45.8 \%)$ in 2007 and increased to $47.5 \%$ in 2013 the number of teenagers who smoked. Pramintari (2014) also states that men are more at risk, the stronger the bonds of friendship and perceptions about smoking, the more risk they are to smoke.

The influence of peers has been widely studied and is significant as a factor in adolescent smoking, various interventions to prevent smoking at this time have been carried out on modifications of peer influence (Cleary, et al, 2015). Smoking prevention efforts must be made so that smoking is not socially acceptable for adolescents (Wiraharja, 2014).

Recognizing various factors causing teenage smoking, health promotion for smoking prevention is done not only to improve their knowledge, adolescents need to be given skills to control themselves, especially from peer influence (Efendy, 2016). Cooperative learning is successfully used by teachers and researchers at various levels of education. In the field of health, especially public health education, cooperative learning is effective when a person teaches his peers about health. (Modeste, 2004).

The effectiveness of the elements of cooperative learning method depends on teachers' knowledge, attitudes and practices on the elements in classroom instructions. This is 
to mean that, if teachers have the necessary knowledge, positive attitudes and practices on the elements and if they effectively implement the elements in the real teaching and learning process, the goals of cooperative learning method are more likely to be achieved. Therefore, unless the elements are implemented meaningfully and properly, teachers should not expect the many positive long-term results of the method (Ali, 2019). Cooperative learning has been shown to stimulate cognitive activity, increase the level of attainment and retention of higher knowledge (Tran, 2014). The existence of knowledge will increase trust in something, in this case knowledge will influence beliefs about health, normative trust and trust in control over health behaviors so that it will influence intentions and ultimately affect the behavior that they have (Ajzen, 2005).

One method of cooperative learning with the principle of interdependence between students is that each student holds information and each student as a source of learning for other students is called a jigsaw technique (Slavin, 2016). Classes with jigsaw techniques have a track record of four decades, effective in increasing positive outcomes. Jigsaws are also known as "puzzle pieces" where the material will be chopped into pieces and pasted on different cards commonly called "jigsaw cards" (Aronson, no year).

In a jigsaw, first each participant will be grouped into small groups and distributed each different jigsaw card, then each participant will separate from the original group and look for people from another group with the same card then join to learn to master the material on the card In the next session, everyone will return to their original group and alternately explain the material they master to other group members (Slavin, 2016) so that each participant is more motivated to contribute to the group (Voyles, 2015).

Based on the previous explanation, the researcher will analyze differences in smoking prevention behavior based on planned behavior theory which consists of attitudes, subjective norms, behavior control, and intentions between before and after the jigsaw intervention.

\section{Research Methods}

Research with quasi experiment type has been carried out in MTS Amin Darussalam which is located on Terusan street, Bandar Setia, Percut Seituan, Deli Serdang, North Sumatra. Research with a sample of 20 people has been collected based on purposive sampling techniques with the aim that the activities take place well, namely students with high, medium and low abilities are placed in the same group in each discussion group. The sample that was collected was given an explanation of the flow of activities, the confidentiality of the data contained in the answer to the questionnaire sheet and requested proof of respondent's willingness by signing an informed consent. The activity starts with:

\subsection{Introduction}

Form small groups of 4-5 students (to make it easier, the number of students in 1 group is adjusted to the number of titles in the reading to be discussed). The facilitator distributes jigsaw cards to each student and explains their assignments to explore (read, understand, discuss and provide information) in accordance with the cards they have.

\subsection{Focused Exploration}

the facilitator instructs all students to form a new group that is a delegation from a small group, that is, those who get a red card gather with another group who gets a red card, as well as other colors, so that a new group is called an expert group because they will become 
experts in the topics contained in each color of the card. The expert group was given \pm 30 minutes to discuss, summarize and understand the contents of the reading in one title that became the burden of his assignment.

\subsection{Report and Reorder}

After the discussion time is up, each student in the expert group returns to the original group, and reports the results of the discussion to the group in a sequence starting from what is a cigarette to how to prevent and stop smoking.

\subsection{Integration and Evaluation}

To find out the results of the discussion, the facilitator asks each participant to answer the quiz (posttest sheet) and which group gets the highest score.

Data before and after intervention was collected using a questionnaire, and analyzed using the Chi-Square test.

\section{Discussion}

The results of the study of differences in the prevention of smoking behavior based on existing elements in the theory of planned behavior are aspects of attitude, subjective norms, $\mathrm{PBC}$ and intentions between before and after the jigsaw intervention then presented in three tables consisting of tables of respondents' characteristics, frequency distribution of smoking prevention behavior before intervention and after the jigsaw intervention, and differences in behavior prevent smoking before the intervention and after the jigsaw intervention.

\subsection{Characteristics of Respondents}

Table I shows the majority of male respondents 0 , did not smoke in the past month 0 there was a desire to smoke 0 , AND was exposed to cigarettes 0 .

Table 1. Frequency distribution of respondent characteristics in MTS Amin Darussalam

\begin{tabular}{|l|l|l|}
\hline Characteristics of respondents & n & \% \\
\hline sex & & \\
\hline Male & & \\
\hline Female & & \\
\hline $\begin{array}{l}\text { Smoking status in the past } \\
\text { month }\end{array}$ & & \\
\hline Never smoked & & \\
\hline Still smoking & & \\
\hline Former smoker & & \\
\hline The desire to smoke & & \\
\hline There is & & \\
\hline There is no & & \\
\hline Exposure to cigarettes & & \\
\hline Very exposed (at risk) & & \\
\hline Exposed & & \\
\hline Not exposed & & \\
\hline Total & 20 & 100,0 \\
\hline
\end{tabular}




\subsection{Frequency Distribution of Knowledge between Before and After the Jigsaw Intervention}

The results of Table 2 show that the majority of respondents before attending the jigsaw class were found to have moderate knowledge by $60 \%$ (12 people) whereas after the intervention of the jigsaw class the majority of respondents with moderate knowledge were increased to $65 \%$ (13 people).

The details of the number of respondents who answered right or wrong from each item of knowledge questions between before and after the intervention in jisaw class showed that the majority of grade VII students were correct in answering the question "Smoking can cause cancer, high blood pressure, stroke and coronary heart disease" By 95\% (19 people).

Table 2. Frequency Distribution of Knowledge before Intervention and After the Jigsaw Intervention in MTS Amin Darussalam

\begin{tabular}{|l|l|l|l|l|}
\hline \multirow{2}{*}{ Knowledge } & \multicolumn{2}{l|}{$\begin{array}{l}\text { Before } \\
\text { Intervention }\end{array}$} & \multicolumn{2}{l|}{$\begin{array}{l}\text { After } \\
\text { Intervention }\end{array}$} \\
\cline { 2 - 5 } & $\mathbf{n}$ & $\mathbf{\%}$ & $\mathbf{n}$ & $\mathbf{\%}$ \\
\hline Less & 4 & 20,0 & 1 & 5,0 \\
\hline middle & 12 & 60,0 & 6 & 30,0 \\
\hline Well & 4 & 20,0 & 13 & 65,0 \\
\hline Total & 20 & 100 & 20 & 100 \\
\hline
\end{tabular}

\subsection{The Frequency Distribution of Respondents' Smoking Prevention Behavior between Before and After the Jigsaw Intervention}

Table 3 shows the majority of respondents before joining the jigsaw class had an attitude in the good category by 45\% (9 people), subjective norms in the medium category by $65 \%$ (13 people), PBC in the good category by 60\% (12 people) and intention in less than $80 \%$ (16 people).

After the jigsaw class intervention found the majority of students had attitudes in the good category by $80 \%$ (16 people), subjective norms in the medium category by $70 \%$ (14 people), PBC in the good category by $95 \%$ (19 people) and intentions in the category less than $60 \%$ (12 people).

Details of the number of respondents who answered right or wrong from each item statement on the aspect of attitude by $90 \%$ (18 people) to disagree with the statement "Smoking adds to my confidence.", Aspects of subjective norms by 100\% (20 people) stated agree "If you are smoking, your friend will advise you ", on the PBC aspect 95\% (19 people) stated" I am ready and will not be ashamed to tell my friends that I do not smoke "and by $40 \%$ (8 people) respondents intend not to smoke and want to convey this intention in front of friends.

Table 3. Frequency Distribution of Behavior Preventing Smoking before Intervention and After Jigsaw Intervention in MTS Amin Darussalam

\begin{tabular}{|l|c|c|c|c|}
\hline \multirow{2}{*}{$\begin{array}{l}\text { Behavior } \\
\text { Preventing }\end{array}$} & \multicolumn{2}{l|}{$\begin{array}{l}\text { Before } \\
\text { Smoking }\end{array}$} & $\mathbf{n}$ & \multicolumn{2}{l|}{$\begin{array}{l}\text { After } \\
\text { Intervention }\end{array}$} \\
\cline { 2 - 5 } & $\mathbf{n}$ & $\mathbf{\%}$ & $\mathbf{n}$ & $\mathbf{\%}$ \\
\hline Attitude & 3 & 15,0 & 2 & 10,0 \\
\hline Less & 8 & 40,0 & 2 & 10,0 \\
\hline Is &
\end{tabular}


Vol. 2, No. 1, February 2020, Page: 214-221

\begin{tabular}{|l|c|c|c|c|}
\hline Well & 9 & 45,0 & 16 & 80,0 \\
\hline Subjective norms & 6 & 30,0 & 2 & 10,0 \\
\hline Less & 13 & 65,0 & 14 & 70,0 \\
\hline Is & 1 & 5,0 & 4 & 20,0 \\
\hline Well & 4 & 20,0 & 0 & 0,0 \\
\hline PBC & 4 & 20,0 & 1 & 5,0 \\
\hline Less & 12 & 60,0 & 19 & 95,0 \\
\hline Is & 16 & 80,0 & 12 & 60,0 \\
\hline Well & 0 & 0,0 & 0 & 0,0 \\
\hline Intention & 4 & 20,0 & 8 & 40,0 \\
\hline Less & 20 & 100,0 & 20 & 100,0 \\
\hline Is &
\end{tabular}

\subsection{Differences in Smoking Prevention Behavior between Before and After the Jigsaw Intervention}

Table 4 shows the attitude of respondents between before and after intervention with jigsaw, there are 12 respondents who have the same attitude between before and after the intervention, there are eight respondents who have a better attitude after intervention and no respondent whose respondents have decreased attitudes after intervention. The test results statistically show the value of $\mathrm{p}=0.005$, compared with an alpha coefficient of 0.05 , the $\mathrm{p}$ value is smaller than alpha. It can be concluded that Ho was rejected, meaning that there were differences in attitude between before and after the jigsaw intervention.

The results show the subjective norms of respondents between before and after intervention with jigsaw, there are 13 respondents who have the same subjective norms between before and after the intervention, there are seven respondents who have better subjective norms after intervention and no respondents whose respondents have subjective norms that are decrease after intervention.

The test results statistically show the value of $\mathrm{p}=0.008$, compared with an alpha coefficient of 0.05 , the value of $\mathrm{p}$ is smaller than alpha. It can be concluded that Ho is rejected, meaning that there are differences in subjective norms between before and after the intervention with Jigsaw. The results showed PBC respondents between before and after intervention with jigsaw, there were 13 respondents who had the same PBC between before and after intervention, there were seven respondents who had better PBC after intervention and none of the respondents whose respondents had PBC decreased after intervention.

The test results statistically show the value of $\mathrm{p}=0.015$, compared with an alpha coefficient value of 0.05 , the $\mathrm{p}$ value is smaller than alpha. It can be concluded that Ho was rejected, meaning that there were $\mathrm{PBC}$ differences between before and after the intervention with jigsaw. The results show the intention of respondents between before and after intervention with jigsaw, there were 16 respondents who had the same intention between before and after the intervention, there were four respondents who had better intentions after the intervention and none of the respondents had decreased intentions after being intervened.

The test results statistically show the value of $p=0.046$, compared with an alpha coefficient value of 0.05 , the $\mathrm{p}$ value is smaller than alpha. It can be concluded that Ho was 
rejected, meaning that there were differences in intentions between before and after the intervention with jigsaw.

Table 4. Behavioral Differences Prevent Smoking Between Before and After Jigsaw Interventions in MTS Amin Darussalam

\begin{tabular}{|c|c|c|c|c|c|c|c|c|c|c|}
\hline \multirow{3}{*}{\begin{tabular}{|l|}
$\mathbf{S}$ \\
$\mathbf{E}$ \\
$\mathbf{B}$ \\
\end{tabular}} & \multirow{3}{*}{ Category } & \multicolumn{6}{|c|}{ After Intervention } & \multirow{2}{*}{\multicolumn{2}{|c|}{ Total }} & \multirow[t]{3}{*}{ P valu } \\
\hline & & \multicolumn{2}{|c|}{ Less } & \multicolumn{2}{|c|}{ Middle } & \multicolumn{2}{|c|}{ Well } & & & \\
\hline & & $\mathrm{n}$ & $\%$ & $\mathrm{n}$ & $\%$ & $\mathbf{n}$ & $\%$ & $\mathbf{n}$ & $\%$ & \\
\hline $\mathbf{E}$ & \multicolumn{10}{|c|}{ Attitude } \\
\hline $\mathbf{L}$ & Less & 2 & 66,7 & 1 & 33,3 & 0 & 0,0 & 3 & 100,0 & \multirow[t]{3}{*}{0,005} \\
\hline $\mathbf{U}$ & Middle & 0 & 0,0 & 1 & 12,5 & 7 & 87,5 & 8 & 100,0 & \\
\hline \multirow[t]{2}{*}{$\mathbf{M}$} & Good & 0 & 0,0 & 0 & 0,0 & 9 & 100,0 & 9 & 100,0 & \\
\hline & \multicolumn{10}{|c|}{ Norm subjective } \\
\hline \multirow{5}{*}{$\begin{array}{l}\mathbf{I} \\
\mathbf{N} \\
\mathbf{T} \\
\mathbf{E}\end{array}$} & Less & 2 & 33,3 & 4 & 66,7 & 0 & 0,0 & 6 & 100,0 & \multirow[t]{3}{*}{0,008} \\
\hline & Middle & 0 & 0,0 & 10 & 76,9 & 3 & 23,1 & 13 & 100,0 & \\
\hline & Good & 0 & 0,0 & 0 & 0,0 & 1 & 100,0 & 1 & 100,0 & \\
\hline & \multicolumn{10}{|c|}{ PBC } \\
\hline & Less & 0 & 0,0 & 0 & 0,0 & 4 & 100,0 & 4 & 100,0 & \multirow{3}{*}{0,015} \\
\hline V & Middle & 0 & 0,0 & 1 & 25,0 & 3 & 75,0 & 4 & 100,0 & \\
\hline $\mathbf{E}$ & Good & 0 & 0,0 & 0 & 0,0 & 12 & 100,0 & 12 & 100,0 & \\
\hline $\mathbf{N}$ & \multicolumn{10}{|c|}{ Desire } \\
\hline $\mathbf{S}$ & Less & 12 & 75,0 & 0 & 0,0 & 4 & 25,0 & 16 & 100,0 & \multirow{3}{*}{0,046} \\
\hline I & Middle & 0 & 0,0 & 0 & 0,0 & 0 & 0,0 & 0 & 0,0 & \\
\hline & Good & 0 & 0,0 & 0 & 0,0 & 4 & 100,0 & 4 & 100,0 & \\
\hline
\end{tabular}

In the aspect of attitude, the test results statistically showed that there were significant differences $(p=0.005)$ of attitude between before and after the intervention with jigsaw. The difference in question is that there are eight respondents who have a better attitude after the intervention and no respondent whose respondents have a decreased attitude after the intervention.

The striking difference in the aspect of attitude after the intervention in the jigsaw group is that the respondents disagreed if cigarettes add to relationships, eliminate or cope with stress and calm the mind. Respondents agreed that quitting smoking is not impossible and the government should increase the price of cigarettes so that school children cannot afford it. In addition to demographic and social influences, a person's attitude to behavior is influenced by the information he has (Ajzen, 2005). In this study the change in attitude after the intervention is in line with the increase in knowledge outcomes after the intervention.

In the aspect of subjective norms, the test results statistically showed that there were significant differences $(p=0.008)$ of subjective norms between before and after the intervention with jigsaw. The difference in question is that there were seven respondents who had better subjective norms after intervention and none of the respondents whose respondents had subjective norms that declined after intervention.

A striking difference from the subjective norm after the intervention in the jigsaw group is in one statement that the respondent agrees that if he is smoking then a friend should advise. This difference is certainly because respondents increased their knowledge about the adverse effects of smoking both active and passive smokers and have a good attitude to prevent smoking. 
Perceptions and interpretations of new information can influence the formation of new behavioral beliefs, normative beliefs and new control trusts (Ajzen, 2005). For PBC, the test results statistically showed that there was a significant difference $(p=0.015)$ of PBC between before and after the jigsaw intervention. The difference in question is that the results of the study show there are as many as seven respondents who have a better PBC after the intervention and no respondent has a PBC that decreases after the intervention.

PBC is the result of control beliefs, if someone has strong control beliefs about the factors that will facilitate a behavior, then that person has a high perception to be able to control a behavior. Conversely, someone has a low perception of behavioral control if that person has strong belief beliefs about the factors that will inhibit the occurrence of behavior (Ajzen, 2005). Behavior to prevent smoking has obstacles because the respondent is still in the adolescent stage which usually someone gives the label "friends" if they have the same beliefs about smoking and the more positive towards smoking the stronger friendship label (Ragan, 2016).

Refusing a friend's invitation to smoke becomes important to discuss, the material in discussion activities is not only to teach healthy living material without cigarettes, respondents are given social skills that are asked to practice instructions on how to refuse smoking invitations from others, especially from friends, respondents practiced alternately so that they would dare to refuse friends to smoke.

The results of this study are in accordance with research conducted by Septiyani (2014) that there is a significant influence on the type of jigsaw cooperative learning model on improving social skills and cognitive learning outcomes. In the aspect of intention, the test results statistically showed that there were significant differences $(p=0.046)$ of intentions between before and after the intervention with jigsaw. The difference in question is that there are four respondents who have better intentions after the intervention and no respondent who has decreased intentions after the intervention.

Behavior is directly influenced by intention and ultimately depends on information that is relevant to the person's behavior. Attitudes, subjective norms, and behavioral control perceptions can influence intentions and conceptually independent, but they can correlate with each other because it may be based on the same information so that new information influences attitudes, subjective norms, PBC and ultimately influences intention (Ajzen, 2005).

Jigsaw has been widely used and is well used in narrative or text material, such as books or description material (Slavin, 2016). Jigsaw has been used successfully in social science (Shaikhi, 2015), scientific science and literacy (Slavin, 2016) including health information literacy (Johnson, 2017).

Jigsaw learning contributes to academic achievement and retention knowledge of Vietnamese students is higher. Students in the experimental group were also asked about their responses to the learning of the jigsaw model. Most of the results were happy to work with others and get explanatory help, discuss, share information, teach others and they enjoyed the jigsaw context. Students in the experimental group stated that jigsaw learning had a positive impact, promoting friendly relations between participants, increasing self-esteem (Tran, 2012) and their learning abilities (Haryono, 2015). 


\section{Conclusion}

From the result and discussion of this research, it can be concluded that the interventions with jigsaw provide differences in attitudes, subjective norms, PBC and intention to prevent smoking between before and after the intervention.

\section{References}

Ali, W. T. (2019). Effects of Cooperative Learning Method (CLM) on Vocabularies and Grammars in Essay Writing. Budapest International Research in Linguistics and Education Sciences (BirLE) Journal. 2(1); 1-11.

Cleary, P.D., et al. 2015. Adolescent Smoking: Research and Health Policy, 66(1): 137-171.

Efendi M., 2016. Studi Multikasus: Epidemi Perilaku Merorok di Kalangan Remajadan Implikasinya dalam Pendidikan. Edcomtech, 1(1) : 69-82.

Haryono, 2015. Learning Achievement Improvement Efforts Course Learn and Learning using the Jigsaw Method and Card Media in Stkip Pgri Ngawi 2014/2015 Academic Year. Journal of Education and Practice.6(30): 94-102.

Johnson H.A., Barret L.C., 2017. Your Teaching Strategy Matters: How Engagement Impacts Application in Health Information Literacy Instruction, JMLA, 105(1) : 44-8.

Kementerian Kesehatan R.I., 2007. Riset Kesehatan Dasar 2007. Jakarta : Badan Penelitian Dan Pengembangan Kesehatan.

Kementerian Kesehatan R.I., 2013. Riset Kesehatan Dasar 2013. Jakarta : Badan Penelitian Dan Pengembangan Kesehatan.

Modeste N.N., Tamatose T.M., 2004. Dictionary of Public Health Promotion and Education. United State : PB Printing.

Pramintari, R.D., Hastuti, D., Djamaludin, M.D., 2014. Pengaruh Gaya Pengasuhan Dan Teman Sebaya Terhadap Perilaku Konsumsi Rokok Siswa Sma Di Kota Bogor. Jurnal Soul. 7(2): 22-34.

Ragan D.T., 2016. Peer Beliefs and Smoking in Adolescence: A Longitudinal Social Network Analysis. Am J Drug Alcohol Abuse. 42(2): 222-230.

Septiyani A.W., Wilujeng I., Susilowati. Pengaruh Model Pembelajaran Kooperatif Tipe Jigsaw TerhadapPeningkatan Keterampilan Sosial Dan Hasil Belajar Kognitif. E-Journal Pendidikan IPA

Shaikhi Fini, A., Zainalipour, H and Homaei, S. 2015. Examining the Effect of Participatory Teaching Methods on Academic Achievement of Boys and Girls in Social Science in the Third Grade of Secondary Schools in the First District in Bandar Abbas. South journal of Educational Psychology and Counseling. 2(1) : 37-43.

Slavin, E. Robert. 2016. Cooperative Learning : Teori, Riset Dan Praktik.Bandung : Penerbit Nusa Media.

Tran V.D., 2012. The Effects of Jigsaw Learning on Students' Attitudes in a Vietnamese Higher Education Classroom. International Journal of Higher Education. 1(2) : 9-20.

Tran V.D., 2014. The Effects of Cooperative Learning on the Academic Achievement and Knowledge Retention. International Journal of Higher Education. 3(2) : 131-40.

Voyles E.C., 2015. New Pieces of the Jigsaw Classroom: Increasing Accountability to Reduce Social Loafing in Student Group Projects. The New School Psychology Bulletin, 3(1) :11-20.

WiraharjaR.S.,SurjadiC.,2014.Why Adolescent Smoke? A Case Study Of North Jakarta, Indonesia. Damianus Journal of Medicine; 13(3) : 208-17.

World Health Organization, 2014. Global Youth Tobacco Survey (GYTS). Luxembourg : WHO press. 